\title{
Molecular cloning of Treponema pallidum outer envelope fibronectin binding proteins, $\mathrm{Pl}$ and $\mathrm{P} 2$
}

\author{
KENNETH PETERSON, JOEL B BASEMAN, JOHN F ALDERETE \\ From the Department of Microbiology, The University of Texas Health Science Center, San Antonio, Texas, \\ United States of America
}

SUMMAR.Y Phages directing the synthesis of Treponema pallidum fibronectin binding adhesin proteins, P1 and P2, ${ }^{1}$ were isolated from an EMBL-3 bacteriophage lambda library of $T$ pallidum deoxyribonucleic acid (DNA). The recombinant phages were identified using antisera generated to treponemal proteins purified in fibronectin-Sepharose. Recombinant P1 and P2 proteins possessed the same relative molecular weights as the native surface polypeptides of spirochaetes. The structural genes for these proteins were subcloned into the plasmid vector pUC19, and transformed Escherichia coli expressed and translocated recombinant P1 and P2 to their outer membranes. Finally, the recombinant adhesin proteins, P1 and P2, were purified from detergent solubilised $E$ coli outer membrane preparations using fibronectin-Sepharose affinity chromatography, which confirmed that the fibronectin binding properties of the cloned proteins were retained.

The spirochaete that causes syphilis, Treponema pallidum, attaches by a specialised tip structure ${ }^{2}$ to both eucaryotic cells and extracellular matrix by the selective recognition of host fibronectin. ${ }^{134}$ Three treponemal proteins designated P1 (molecular weight 89300 daltons), P2 (37000 daltons), and P3 (32000 daltons), which are located on the spirochaete outer envelope, have been implicated as putative adhesins, ${ }^{56}$ and have been purified subsequently by fibronectin-Sepharose affinity chromatography. ${ }^{1}$

The inability to cultivate large quantities of $T$ pallidum organisms has impeded our attempts to identify the functional domains of the treponemal adhesins that recognise host fibronectin. ${ }^{7}$ Recombinant deoxyribonucleic acid (DNA) techniques provide a means of obtaining sufficient quantities of specific treponemal proteins to purify and subsequently characterise them. ${ }^{8-11}$

Because the fibronectin binding proteins of $T$ pallidum represent the only treponemal surface proteins with assigned biological properties, ${ }^{13}$ the availability of recombinant adhesins offers opportunities for testing rational vaccines and diagnostic probes for syph-

Address for reprints: Dr John F Alderete, Department of Microbiology, The University of Texas Health Science Center, 7703 Floyd Curl Drive, San Antonio, Texas 78284, USA

Accepted for publication 12 March 1987 ilis and other treponematoses. In this study we describe the molecular cloning of the structural genes for the fibronectin binding adhesin proteins of treponemes. We discuss the availability of the recombinant adhesins for the future understanding of the complex interaction between host and parasite and of the pathogenesis of syphilis.

\section{Materials and methods}

\section{BACTERIA}

Treponema pallidum organisms were maintained by serial passage in the testes of New Zealand white rabbits, and treponemes were harvested from testicular tissue as described previously. ${ }^{269}$ Spirochaetes separated from host material were used for attachment assays at densities of $1 \times 10^{9}$ organisms $/ \mathrm{ml} .{ }^{13}$ About $4 \times 10^{9}$ motile spirochaetes in $10 \mathrm{ml}$ of treponemal medium were radiolabelled with $2.0 \mathrm{mCi}$ of radiosulphated $\left({ }^{35} \mathrm{~S}\right)$ methionine (specific activity, 1500 $\mathrm{Ci} / \mathrm{mmole}$; Amersham Corporation, Arlington Heights, Illinois, USA) for two hours at $34^{\circ} \mathrm{C}$ under aerobic conditions. ${ }^{16}$ Radiolabelled organisms were then pelleted at $15000 \times g$ and resuspended in phosphate buffered saline (PBS) for use in attachment assays.

E coli strains LE392 ${ }^{12}$ (F; hsdR 514, supE 44, supF 58, lac $Y$, galK 2, galT 22, metB, trpR 55, lambda ${ }^{-}$) 
and $\mathrm{TB} 1^{12}$ ( $\Delta$ lac-pro, strA, ara, thi, $\phi 80 \mathrm{dlacZ}, \Delta \mathrm{M} 15$ $h s d R$ ) were grown in Luria broth. ${ }^{12}$

\section{ANTISERA}

Serum from syphilitic rabbits was obtained from intratesticularly inoculated rabbits housed for at least 40 days before infection, ${ }^{13}$ and was extensively adsorbed against $E$ coli before its use in immunoblots of recombinant $E$ coli proteins. ${ }^{911}$ Antisera to treponemal fibronectin binding proteins designated P1, P2, and $\mathrm{P} 3$ were prepared by immunising rabbits ${ }^{7}$ with fibronectin-Sepharose purified treponemal proteins. ${ }^{1}$ These antisera were adsorbed with an extract of $E$ coli obtained in a French pressure cell apparatus ${ }^{9}$ and with fibronectin coupled to Sepharose ${ }^{1}$ so that no reactivity existed for $E$,coli proteins or fibronectin. IgG fractions of these antisera were prepared by protein A-Sepharose affinity chromatography. Serum from patients with syphilis was provided by Sandra Larsen of the Centers for Disease Control, Atlanta, Georgia. ${ }^{14}$ Serum samples from healthy rabbits and from people without a history of sexually transmitted diseases were used as controls.

ATTACHMENT OF T PALLIDUM TO FIBRONECTIN COATED COVERSLIPS AND HEP-2 CELLS

Glass coverslips coated with fibronectin were prepared as described previously. ${ }^{1-3}$ Human epithelial cells (HEp-2; ATCC, Rockville, Maryland, USA) were passaged in Dulbecco's minimum essential (DME) medium supplemented with $10 \%$ fetal calf serum, and $5 \times 10^{4}$ HEp-2 cells were seeded in Leighton tubes containing individual $9 \times 35 \mathrm{~mm}$ coverslips for 24 hours before attachment assays.

Freshly extracted $T$ pallidum organisms or intrinsically labelled spirochaetes were treated with IgG antibody $(500 \mathrm{mg} / \mathrm{l})$ for one hour before being incubated for two hours at $34^{\circ} \mathrm{C}$ with fibronectin coated coverslips or HEp-2 cells. ${ }^{1-3}$ The coverslips were then removed and rinsed nine times by immersion in a beaker containing PBS before each was placed in a vial with scintillation fluid to determine adherent radioactivity. ${ }^{136}$

AFFINITY PURIFICATION OF PROTEINS P1, P2, AND P3 WITH FIBRONECTIN-SEPHAROSE

Adhesin proteins from $T$ pallidum organisms were isolated by fibronectin-Sepharose affinity chromatography. ${ }^{1}$ Recombinant proteins $\mathrm{P} 1$ and $\mathrm{P} 2$ were purified similarly using outer membranes of transformed $E$ coli. Briefly, $1 \mathrm{ml}$ containing about $100 \mathrm{mg}$ of $E$ coli outer membranes prepared as outlined below was solubilised adding $100 \mu \mathrm{l}$ of $10 \%$ Zwittergent 3-12 (Z(3-12); Calbiochem-Boehring). This extract was then homogenised and diluted in PBS to give a final $Z(3-12)$ detergent concentration of $0.05 \%$ for chromatography. ${ }^{1} \quad E$ coli proteins adherent to fibronectin were released by boiling the extract in electrophoresis dissolving buffer, and were used in immunoblotting.

IMMUNOLOGICAL SCREENING OF T PALLIDUM DNA CLONE BANK PREPARED BY Bam HI AND Sal I DIGESTION

A clone bank prepared in bacteriophage $\lambda$ EMBL-3 using $T$ pallidum DNA partially digested by Bam HI was described in an earlier study. ${ }^{911}$ A clone bank of $T$ pallidum DNA treated with Sal I was also constructed similarly. Recombinant phages were plated on $E$ coli LE392 to produce about 500 plaques per plate. The plates were overlaid with nitrocellulose discs, which were incubated at $4^{\circ} \mathrm{C}$ overnight, removed, and screened with antisera prepared against $T$ pallidum proteins adherent to fibronectin. ${ }^{13}$ Clones producing signals were screened again in duplicate for positive reactions, and were immunoblotted.

\section{CONSTRUCTION OF PLASMIDS CONTAINING PI AND P2 STRUCTURAL GENES}

Recombinant phages producing a recombinant treponemal protein reactive with specific antisera to the treponemal fibronectin binding proteins were amplified and purified from two L cultures of $E$ coli LE392. The phage DNA was isolated ${ }^{12}$ and enzymatically digested with Bam HI (P1 encoding phage) and SalI (P2 encoding phage). Insert fragments of $6.6 \mathrm{~kb}$ for $\mathrm{P} 1$ and $5.2 \mathrm{~kb}$ for $\mathrm{P} 2$ were ligated individually into the respective Bam HI or Sal I sites of the plasmid vector, pUC19. Ligated DNA was then used to transform $E$ coli TB1. Colonies displaying a white phenotype were analysed by sodium dodecyl sulphate polyacrylamide gel electrophoresis (SDS-PAGE) and immunoblotting to express P1 and P2 proteins.

\section{FRACTIONATION OF E COLI CELLS}

The subcellular location of recombinant P1 and P2 was established by differential centrifugation of $E$ coli treated in a French pressure cell apparatus. ${ }^{15}$ One litre of $E$ coli growing at the mid-logarithmic phase was harvested by centrifugation and washed once with $10 \mathrm{mmol} / \mathrm{l} \mathrm{N}-2$-hydroxyethyl piperazine- $\mathrm{N}-2$ ethane sulphonic acid (HEPES) buffer, pH 4. The bacteria were resuspended in $30 \mathrm{ml}$ HEPES buffer and treated at 20000 psi on a French pressure cell apparatus. The membrane fractions were then separated by centrifugation as described previously. ${ }^{911} 15$

\section{SDS-PAGE AND IMMUNOBLOTTING}

SDS-PAGE and immunoblotting of $T$ pallidum or $E$ coli proteins have been described previously. ${ }^{156}$ Total trichloroacetic acid protein preparations of $T$ 
pallidum were prepared for electrophoresis and immunoblotting as detailed elsewhere. ${ }^{6}$

\section{Results}

\section{SPECIFICITY OF ANTISERA GENERATED}

\section{AGAINST $T$ PALLIDUM FIBRONECTIN BINDING} PROTEINS

It was important first to establish the specificity of antibodies generated in rabbits to $T$ pallidum adhesins P1, P2, and P3 purified by fibronectin-Sepharose chromatography. ${ }^{1}$ Using an extract of detergent solubilised $T$ pallidum that contained numerous treponemal proteins (fig 1, lane A), the selective immunodetection of the previously identified adhesins was shown (lane C). ${ }^{1}$ In contrast, syphilitic rabbit serum recognised many additional $T$ pallidum polypeptides in a duplicate blot of the same extract (lane B). Antisera to P1, P2, and P3 failed to recognise proteins of the non-pathogenic spirochaete, Treponema phagedenis biotype Reiter (data not shown).

Incubating of $T$ pallidum with the IgG fraction of syphilitic rabbit serum or with antisera to $\mathrm{P} 1, \mathrm{P} 2$, and $\mathrm{P} 3$ proteins before adding treponemes to coverslips coated with fibronectin or to HEp-2 cell monolayers ${ }^{13}$ decreased treponemal binding by more than half. Treating organisms with normal rabbit IgG did not diminish binding to fibronectin or to HEp-2 cells, as we have reported previously. ${ }^{1-36}$

\section{PHAGE CLONES EXPRESSING T PALLIDUM \\ PROTEINS P1 AND P2}

An EMBL-3 phage library obtained from $T$ pallidum DNA digested with Bam HI and Sal I was screened with antisera to treponemal proteins that bind fibronectin. Phages producing positive signals were cloned and their lysates analysed by immunoblot using pooled serum from people with syphilis. Two distinct patterns of immunoreactivity were detected (fig 2). We observed recombinant proteins that comigrate with P1 (lane B1) and with P2 (lane C1). Lane A shows immunoblot profiles of proteins $\mathrm{P} 1, \mathrm{P} 2$, and $\mathrm{P} 3$ using total $T$ pallidum proteins and the antisera to treponemal proteins that bind fibronectin. Plaque purified antibodies ${ }^{9}$ recognised the same proteins (lanes B2 and C2, respectively), which suggested that the structural genes for these two $T$ pallidum proteins were entirely cloned.

PLASMID EXPRESSION OF PI AND P2 IN E COLI To facilitate further analysis of recombinant $\mathrm{Pl}$ and $P 2$, we subcloned their respective structural genes into the multicopy expression plasmid, pUC19. The phage derived $T$ pallidum insert DNA was ligated into pUC19, and an attempt was made to transform $E$ coli. Colonies displaying a white phenotype were

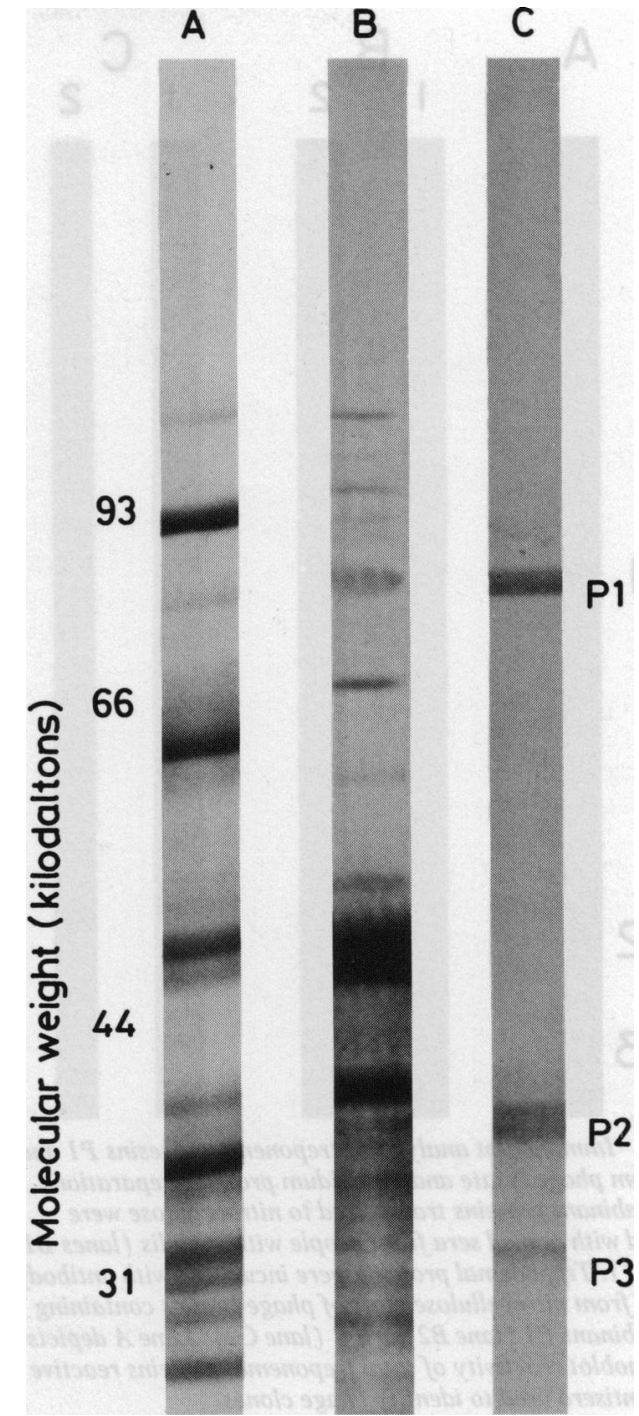

Fig 1 Immunoblot reactivity of anti-P1, P2, and P3 sera to total Treponema pallidum proteins. Proteins were stained with Coomassie brilliant blue (lane A) or electrophoretically transferred to nitrocellulose and incubated with syphilitic rabbit sera (lane B) or sera from rabbits immunised with $T$ pallidum fibronectin binding proteins (lane $C$ ).

screened by immunoblot using antisera to $\mathrm{P} 1, \mathrm{P} 2$, and $\mathrm{P} 3$. We isolated clones that expressed the treponemal adhesin proteins, $\mathbf{P 1}$ and $\mathrm{P} 2$.

Finally, we identified the cellular location of P1 and $\mathrm{P} 2$ in $E$ coli transformed by pUC19. Figure 3 shows recombinant proteins $\mathrm{P} 1$ and $\mathrm{P} 2$ in both the cytoplasmic and outer membrane fractions of recombinant $E$ coli. 


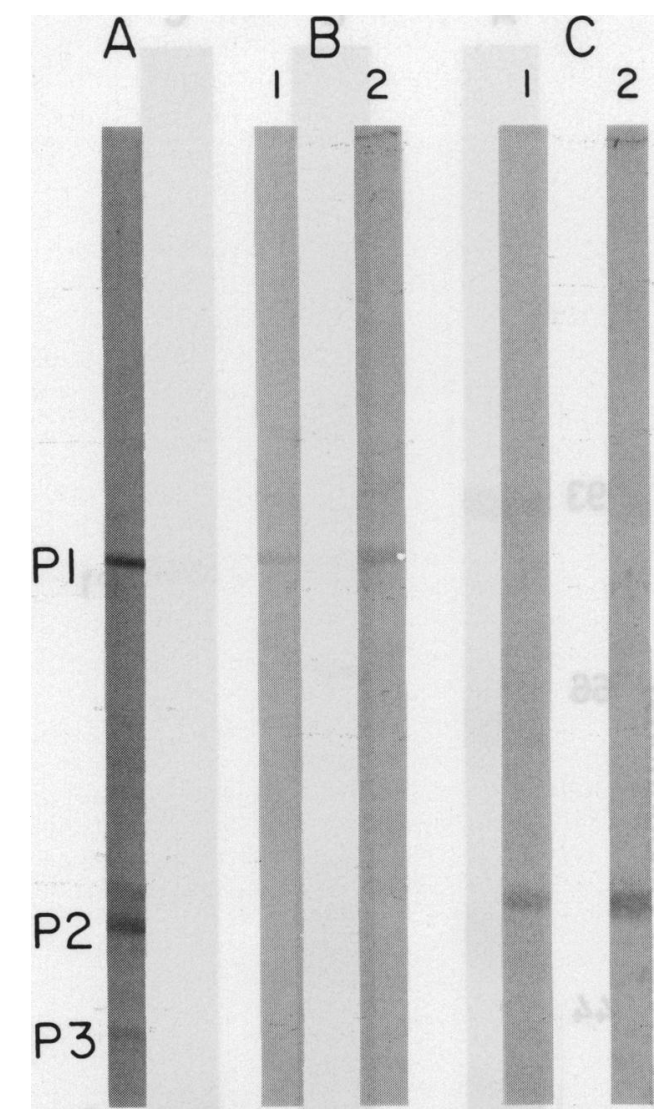

Fig 2 Immunoblot analysis of treponemal adhesins P1 and $P 2$ from phage lysate and $T$ pallidum protein preparations. Recombinant proteins transferred to nitrocellulose were probed with pooled sera from people with syphilis (lanes BI and (1). Treponemal proteins were incubated with antibody eluted from nitrocellulose blots of phage lysates containing recombinant $P 1$ (lane $B 2$ ) or $P 2$ (lane $C 2$ ). Lane A depicts immunoblot reactivity of total treponemal proteins reactive with antisera used to identify phage clones.

\section{AFFINITY PURIFICATION OF RECOMBINANT PI} AND P2 USING FIBRONECTIN-SEPHAROSE

To demonstrate the fibronectin binding ability of recombinant $\mathrm{P} 1$ and $\mathrm{P} 2$, a $\mathrm{Z}(3-12)$ detergent extract of outer membranes of recombinant $E$ coli expressing either P1 or P2 was chromatographed on fibronectin-Sepharose. Analysis by immunoblot of adherent material using antisera to proteins P1, P2, and $\mathrm{P} 3$ showed the presence of recombinant $\mathrm{P} 1$ or $\mathrm{P} 2$ (fig 4, lanes Al and B1), which comigrated with Pl and P2 purified from $T$ pallidum detergent extracts. Non-adherent material evaluated similarly (fig 4, lanes A2 and B2) failed to react in the immunoblot

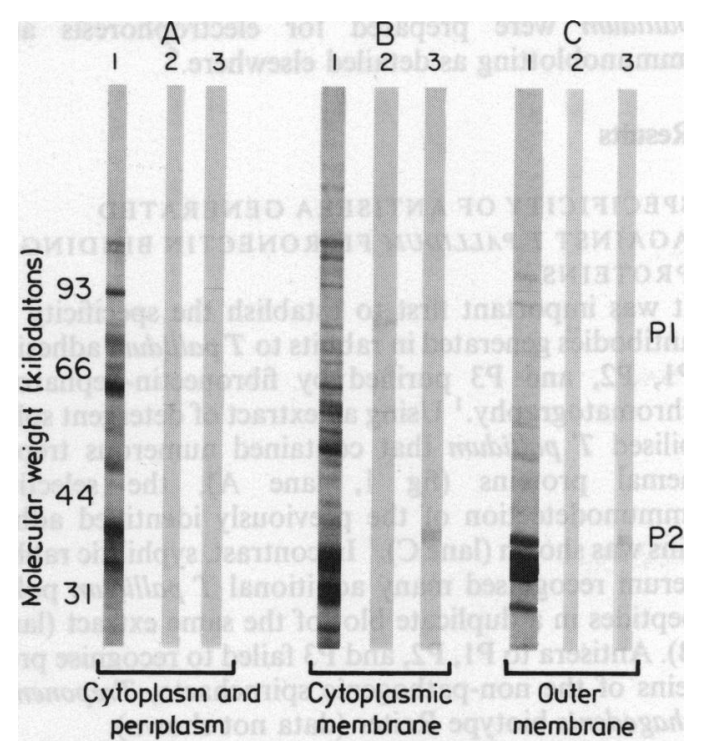

Fig 3 Immunoblot localisation of $P 1$ and P2 in transformed Escherichia coli. Recombinant E coli cells were treated in French pressure cell apparatus and separated into cytoplasm and periplasm, cytoplasmic membrane, and outer membrane fractions. Protein fractions were electrophoresed and stained with Coomassie brilliant blue (lanes A1, B1, and C1) or blotted on to nitrocellulose and incubated with syphilitic rabbit serum (lanes $A 2, A 3, B 2, B 3, C 2$ and $C 3$ ).

assay. As an additional control in the experiment, an outer membrane preparation of $E$ coli containing a plasmid expressing a 70000 dalton treponemal protein not recognised by antisera to the fibronectin binding proteins (P1, P2, and P3) was detected only in the non-adherent fraction when probed with syphilitic rabbit serum (fig 4 , lanes $\mathrm{Cl}$ and $\mathrm{C} 2$ ). Under similar experimental conditions fibronectinSepharose chromatography of a total detergent extract of $T$ pallidum showed the selective purification and immunoreactivity of $\mathrm{P} 1, \mathrm{P} 2$, and $\mathrm{P} 3$.

\section{Discussion}

Molecular examination of the interactions of $T$ pallidum with eukaryotic cell surfaces identified three outer envelope treponemal proteins as putative ligands. ${ }^{156}$ In separate studies examining treponemal acquisition of host macromolecules, the putative adhesins showed high affinity for fibronectin. ${ }^{13}$ Additionally, antibodies to fibronectin but not to other components of the extracellular matrix greatly diminished treponemal parasitism of host cells. ${ }^{3}$ Other observations reinforced the idea of receptor to ligand specificity for interactions between $T$ pallidum and host cells. ${ }^{1-36}$ 


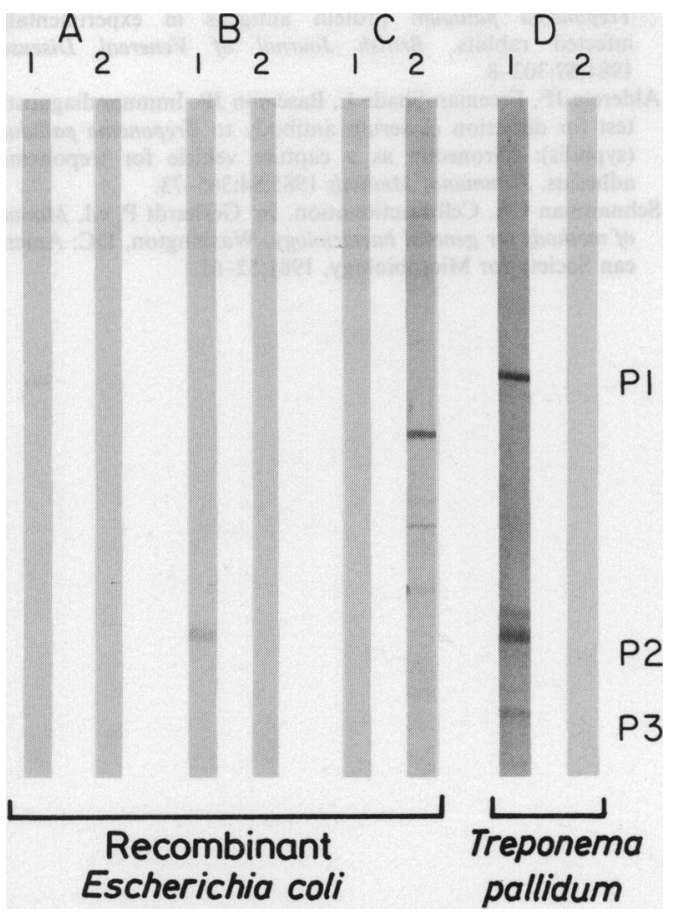

Fig 4 Immunoblot analysis of fibronectin-Sepharose chromatographed protein preparations. Recombinant Ecoli outer membrane proteins (lanes $A$ to $C$ ) and $T$ pallidum organisms (lane D) were detergent solubilised and chromatographed on fibronectin-Sepharose affinity columns. Profiles of immunoblots with syphilitic rabbit serum of adherent fractions from $E$ coli producing $P 1$ (lane A1), P2 (lane B1), and a 70 kilodalton treponemal protein (lane $C 1$ ) and T pallidum (lane D1). Lanes A2, B2, C2, and D2 show immunoblot profiles of non-adherent fractions from the same protein preparations.

Using fibronectin-Sepharose affinity purified treponemal preparations we were able to generate antibodies with specificity for $T$ pallidum proteins $\mathrm{P} 1, \mathrm{P} 2$, and P3 (fig 1). These antibodies inhibited attachment of treponemes to fibronectin and to HEp-2 cells and were used to screen the $T$ pallidum genomic library ${ }^{12}$ for expressing these biologically important peptides. Distinct phage clones directing the synthesis of 89300 dalton (P1) and 37000 dalton (P2) proteins were isolated. The treponemal origin of the structural genes of these proteins was shown by the ability of antibodies purified from blots of phage lysates to react with native $T$ pallidum proteins of identical molecular weight (fig 2).

The respective phage DNAs encoding P1 and P2 were subcloned into the expression plasmid, pUC19. The resulting recombinant plasmids directed the expression of these proteins in transformed $E$ coli.
Furthermore, the plasmid encoded proteins were transferred to $E$ coli outer membranes (fig 3). Fibronectin chromatography of detergent solubilised $E$ coli outer membranes showed the affinity of recombinant P1 and P2 for fibronectin (fig 4), which indicated that the recombinant proteins, $\mathrm{P} 1$ and $\mathrm{P} 2$, retained functional integrity and can be used to identify their putative common fibronectin binding domain. $^{7}$

Furthermore, immunoblot analysis of the recombinant adhesins with sera from people with syphilis (fig 2, lanes B1 and $\mathrm{Cl}$ ) reinforced reports that detailed the immunogenicity of P1 and P2.25613 This evidence provides the basis for molecular dissection of immunodominant epitopes in the native adhesins using recombinant peptides. Whether immune reactivity to these important functional immunogens is humoral or cellular may now be decided. Such information may also assist in clarifying the role of immune processes in treponemal infections.

This work was supported by a grant Al-19566 from the National Institutes of Allergy and Infectious Diseases and by Cistron Biotechnology. JFA is the recipient of National Institutes of Health (NIH) research career development award KO4 AI-00584. KMP was supported by training grant 1-T32AI-07271 from NIH.

\section{References}

1 Peterson KM, Baseman JB, Alderete JF. Treponema pallidum receptor binding proteins interact with fibronectin. J Exp Med 1983;157:1958-70.

2 Hayes NS, Muse KE, Collier AM, Baseman JB. Parasitism by virulent Treponema pallidum of host cell surfaces. Infect Immun 1977;17:174-81.

3 Thomas DD, Baseman JB, Alderete JF. Fibronectin mediates Treponema pallidum cytadherence through recognition of fibronectin cell-binding domain. J Exp Med 1985;161:514-25.

4 Thomas DD, Baseman JB, Alderete JF. Enhanced levels of attachment of fibronectin-primed Treponema pallidum to extracellular matrix. Infect Immun 1986;52:736-41.

5 Baseman JB, Hayes EC. Molecular characterization of receptor binding proteins and immunogens of virulent Treponema pallidum. J Exp Med 1980;151:573-86.

6 Alderete JF, Baseman JB. Surface characterization of virulent Treponema pallidum. Infect Immun 1980;30:814-23.

7 Thomas DD, Baseman JB, Alderete JF. Putative Treponema pallidum cytadhesins share a common functional domain. Infect Immun 1985;49:833-5.

8 Fehniger ET, Walfield AM, Cunningham TM, Radolf JD, Miller JN, Lovett MA. Purification and characterization of a cloned protease-resistant Treponema pallidum specific antigen. Infect Immun 1984;46:598-603.

9 Peterson KM, Baseman JB, Alderete JF. Isolation of a Treponema pallidum gene encoding immunodominant outer envelope protein P6 which reacts with sera from patients at different stages of syphilis. J Exp Med 1986;164:1160-70.

10 Peterson KM, Morse EP, Baseman JB, Alderete JF. Cloning of genes for Treponema pallidum proteins and analysis of an outer envelope recombinant protein. In: Agabian N, Goodman H, 
Noguiera N, eds. Molecular strategies of parasitic invasion. New York: Alan R Liss, 1987:735-44.

11 Peterson KM, Baseman JB, Alderete JF. Cloning structural genes for Treponema pallidum immunogens and characterization of recombinant treponemal surface protein P2 (P2 star). Genitourin Med 1987;63:289-96.

12 Maniatis T, Fritsch EF, Sambrook J. Construction of genomic libraries. In: Molecular cloning: a laboratory manual. New York: Cold Spring Harbor Laboratory, 1982:269-93.

13 Alderete JF, Baseman JB. Analysis of serum IgG against

Treponema pallidum protein antigens in experimentally infected rabbits. British Journal of Venereal Diseases 1981;57:302-8.

14 Alderete JF, Freeman-Shade L, Baseman JB. Immunodiagnostic test for detection of serum antibody to Treponema pallidum (syphilis): fibronectin as a capture vehicle for treponemal adhesins. J Immunol Methods 1985;84:365-73.

15 Schnaitman CA. Cell fractionation. In: Gerhardt P, ed. Manual of methods for general bacteriology. Washington, DC: American Society for Microbiology, 1981:52-61. 